\title{
The Fear of Gastric Cancer in Patients with Dyspepsia: Challenge in Specialist Care Gastroenterology
}

\author{
Lukas Macke Christian Schulz Peter Malfertheiner \\ Department of Medicine II, University Hospital, LMU Munich, Munich, Germany
}

\section{Keywords}

Dyspepsia - Gastritis · Atrophic gastritis · Intestinal metaplasia - Gastric cancer · Helicobacter pylori · Eradication therapy

\begin{abstract}
Background: Dyspepsia is one of the most common complaints in gastroenterology. While its etiology is usually benign, rare cases of malignancy have to be identified. Individualized risk stratification is essential for cost-effective management of dyspepsia. Here, we discuss the challenges of investigating dyspepsia at the specialist level and provide a framework for rational workup and surveillance strategies. Summary: Causes of dyspepsia can be functional or organic, including gastritis, peptic ulcers, or malignancy. H. pylori gastritis represents a specific entity of dyspepsia and increases the risk of gastric cancer. H. pylori eradication can improve symptoms in a subset of patients and reduce gastric cancer risk. In young patients without alarm features, malignancy is rare, and noninvasive testing for $\mathrm{H}$. pylori is appropriate. In elder patients and those with alarm features, high-quality endoscopy is the method of choice to rule out malignancy. Advanced corpus-predominant atrophic gastritis with or without intestinal metaplasia represent precancerous lesions. Key Messages: Symptom assessment requires to dis-
\end{abstract}

karger@karger.com www.karger.com/ddi

(C) 2021 S. Karger AG, Base

Karger" tinguish dyspepsia of functional or organic origin. Risk stratification in dyspeptic patients is based on age, alarm features, and $H$. pylori status. Noninvasive test-and-treat is recommended in patients with low gastric cancer risk, while endoscopy is recommended in individuals at increased risk. H. pylori infection should be eradicated in order to obtain a symptomatic benefit and reduce gastric cancer risk. Advanced preneoplastic lesions require endoscopic surveillance.

(c) 2021 S. Karger AG, Basel

\section{The Burden of Gastroduodenal Disorders}

Dyspepsia covers a spectrum of single or combined symptoms attributable to the gastroduodenal region, defined by epigastric burning or pain, postprandial fullness, early satiety, bloating, excessive belching, and nausea [1]. In a recent large-scale questionnaire-based, multinational study, the prevalence of gastroduodenal complaints according to the Rome IV criteria was estimated at $10.6 \%$ (95\% CI: 10.4-10.9\%) [2]. A meta-analysis found a pooled global prevalence of uninvestigated dyspepsia of $21 \%$ with large variation among countries and according to the diagnostic criteria applied (1.8-57.0\%). Female gender, smoking, nonsteroidal drug use, and $H$. pylori infec- 
Table 1. Possible causes of symptoms of dyspepsia
- Functional dyspepsia

- H. pylori infection

- Non-H. pylori gastritis (e.g., autoimmune, chemical, and eosinophilic)

- Peptic ulcer disease

- Gastric cancer, esophagogastric junction cancer

- Gastroparesis (autonomic neuropathy, iatrogenic)

- Drugs (e.g., nonsteroidal anti-inflammatory drugs, iron, and opioids)

- Gallstones, sphincter of Oddi dysfunction, biliary dyskinesia, cholangiocarcinoma

- Chronic pancreatitis, pancreatic cancer

- Hepatocellular carcinoma

- Parasites (e.g., Giardia lamblia, Strongyloides spp., and Anisakis spp.)

- Vascular (e.g., celiac artery compression syndrome and chronic mesenteric ischemia)

- Autoimmune diseases (e.g., Crohn's disease and celiac disease) tion were identified as independent, yet moderate risk factors [3]. Dyspepsia is not associated with increased mortality but reduces quality of life and places a significant economic burden on the patient and the community, via direct medical costs and indirect costs due to absenteeism and loss of productivity [4-8].

\section{Etiologies of Dyspepsia}

A wide range of gastroduodenal diseases may cause dyspeptic symptoms. They include gastritis of different etiologies, gastroduodenal erosions and ulcers, malignancies including gastric carcinoma, MALT lymphoma, or gastrointestinal stromal tumors, gastroesophageal reflux disease, and pancreaticobiliary, vascular, and autoimmune diseases (Table 1).

In a cohort of 2,741 primary care dyspeptic patients without alarm symptoms, endoscopy detected abnormalities in $23 \%$ of patients. The most common findings were reflux esophagitis with erosions (15\%), gastric ulcers (2.7\%), and duodenal ulcers $(2.3 \%)$. The prevalence of upper gastrointestinal malignancy was $0.22 \%$ (6 cases, $3 \times$ gastric cancer, $3 \times$ esophageal cancer). If in this cohort, only dyspeptic patients over 50 years had undergone endoscopy, 1 esophageal cancer and no gastric cancers would have been missed. The study was conducted in 17 countries in 5 continents, but the majority of patients was recruited in low-prevalence regions of $H$. pylori and gastric cancer. It should be noted that patients were not routinely biopsied in the absence of visible pathology to detect $H$. pylori gastritis or preneoplastic changes [9]. A meta-analysis on the frequencies of upper gastrointestinal endoscopic findings in unselected population samples reported a pooled prevalence of esophagitis of $11.2 \%$, en- doscopically suspected esophageal metaplasia 5.1\%, peptic ulcer $6.8 \%$, and gastric cancer $0.33 \%$. The prevalence of $H$. pylori was positively associated with the prevalence of peptic ulcer $(r=0.91)$ but negatively associated with the prevalence of esophagitis $(r=0.99)$ [10]. These data show that in low-prevalence regions of $H$. pylori and gastric cancer, upper gastrointestinal malignancy is a rare differential diagnosis in patients with dyspepsia below an age threshold of 50 years. Importantly, the majority of organic pathologies, represented by reflux esophagitis, $H$. pylori gastritis, and peptic ulcer disease, will be treated adequately by a combination of noninvasive testing and treatment for $H$. pylori and/or empirical therapy with proton pump inhibitors (PPIs).

If underlying organic, systemic, or metabolic disease has been ruled out in routine clinical testing, $>70 \%$ of patients with dyspeptic symptoms will be classified as having functional dyspepsia [1, 10]. The current Rome IV criteria redefined the spectrum of functional gastrointestinal disorders as disorders of gut-brain interaction. They often occur in combinations including motility disturbance, visceral hypersensitivity, altered mucosal and immune function, altered gut microbiota, and altered central nervous system processing. Functional dyspepsia is categorized among the gastroduodenal disorders and subclassified into postprandial distress syndrome and epigastric pain syndrome, although significant overlap may exist between these entities $[1,11,12]$.

\section{H. pylori-Related Dyspepsia}

H. pylori is the most prevalent bacterial pathogen in humans, infecting approximately half of the world's population with large regional differences [13]. H. pylori is 
specifically adapted to colonize the stomach mucosa and causes chronic-active gastritis in each infected individual. A proportion of individuals will develop complications that include peptic ulcer disease, intestinal-type adenocarcinoma, or MALT lymphoma [14]. H. pylori causes approximately $90 \%$ of all gastric cancer cases worldwide, excluding those located at the gastroesophageal junction which are a distinct entity $[15,16]$. Gastric carcinogenesis is a multistep process where chronic-active gastritis progresses to atrophic gastritis with or without intestinal metaplasia, which represent precancerous lesions for gastric cancer [17]. The Kyoto Consensus in 2015 led to a paradigm shift in the management of $H$. pylori infection and defined $H$. pylori gastritis as an infectious disease irrespective of symptoms and complications, resulting in the recommendation to offer treatment to all infected individuals [18].

Clinical observations indicate an association between H. pylori and dyspepsia in a subset of patients: in subjects randomly recruited at primary care centers in the UK, presence of $H$. pylori infection as determined by the 13C urea breath test (UBT) increased the risk for dyspeptic symptoms (OR 1.21; 95\% CI: 1.09-1.34), suggesting that $5 \%$ of dyspepsia in the population is attributable to H. $p y$ lori [19]. Similar observations were made in populationbased Danish cohorts with positive UBT or increased levels of IgG antibodies to $H$. pylori $[20,21]$. In a cohort of Chinese individuals undergoing endoscopic gastric cancer screening, $H$. pylori specifically increased the risk for postprandial distress syndrome (OR 1.86; 99.5\% CI: 1.013.45) but not for epigastric pain syndrome, according to the Rome III criteria, an effect attributable to more severe antral mucosal atrophy and CagA-positive H. pylori strains [22].

Early trials on the effect of $H$. pylori eradication on dyspeptic symptoms yielded discouraging results [2326], but later trials confirmed a moderate but significant tendency toward symptomatic benefits: The German ELAN (Eradication vs. Lansoprazole in H. pylori-Associated Nonulcer dyspepsia) study randomized 800 patients with dyspeptic symptoms and endoscopically confirmed $H$. pylori infection in the absence of other upper gastrointestinal pathology to receive 2 different regimens of clarithromycin-based eradication therapy versus PPI alone. Successful eradication was associated with significant improvement in dyspeptic symptoms, represented by a $12 \%$ reduction in the nonulcer dyspepsia symptom score and by complete symptom resolution in $41.5 \%$ patients in the antibiotic treatment groups versus $33.2 \%$ in the PPI group, resulting in a number needed to treat
(NNT) of 12 [27]. Although heterogeneous in the criteria applied to assess dyspepsia and to quantify symptom improvement, the symptomatic benefit of $H$. pylori eradication was confirmed in numerous studies in different ethnic backgrounds [28-31] and in subsequent meta-analyses [32-35], finding NNTs between 8 and 15 .

Based on this evidence, the Kyoto Consensus 2015 recognized $H$. pylori gastritis as a distinct entity of dyspepsia and recommended $H$. pylori eradication as first-line treatment for H. pylori-infected dyspeptic patients [18]. To date, it is unclear which subset of $H$. pylori-infected patients with dyspepsia will experience symptomatic benefit from eradication therapy.

\section{Workup of Dyspepsia}

The burden of dyspeptic symptoms in the general population and its usually benign etiology require a rational workup based on the individual patient's risk. Management of dyspepsia should be based on age, medical and family history, physical examination, and the presence of alarm features. Laboratory testing and imaging studies, for example, sonography, may be applied to rule out pancreaticobiliary, vascular, and autoimmune disease in patients with upper abdominal complaints. Endoscopy is the gold-standard test for diagnosing esophageal and gastric malignancy at an early stage, but it is expensive and invasive with a residual risk of serious adverse events $[9$, 36].

Numerous randomized trials have shown that noninvasive test-and-treat strategies in young patients are as efficient and safe as prompt endoscopy for management of dyspeptic patients [37-41]. For example, in 432 Asians under 45 years with dyspepsia who were randomized to noninvasive test-and-treat for $H$. pylori versus prompt endoscopy, there was no difference in symptom change and no upper gastrointestinal malignancy detected at 12 months, but at twice the total cost (USD 179.05 vs. USD $87.10, p=0.0001)$, higher follow-up costs after the initial diagnostic test (USD 48.40 vs. USD 64.5, $p=0.007$ ), and higher medication consumption in the endoscopy group. However, patient satisfaction was higher in the endoscopy group [42]. In the study by Vakil et al. [9] described above, the cost for detecting 1 upper gastrointestinal malignancy in dyspeptic patients in low-prevalence regions for H. pylori was calculated at USD 45,683-228,417 (for endoscopy costs USD 100-500) if the entire population were endoscoped and 16,580-82,900 USD if endoscopy was limited to the population $>50$ years. 
Fig. 1. Algorithm for workup of dyspepsia in adult patients.

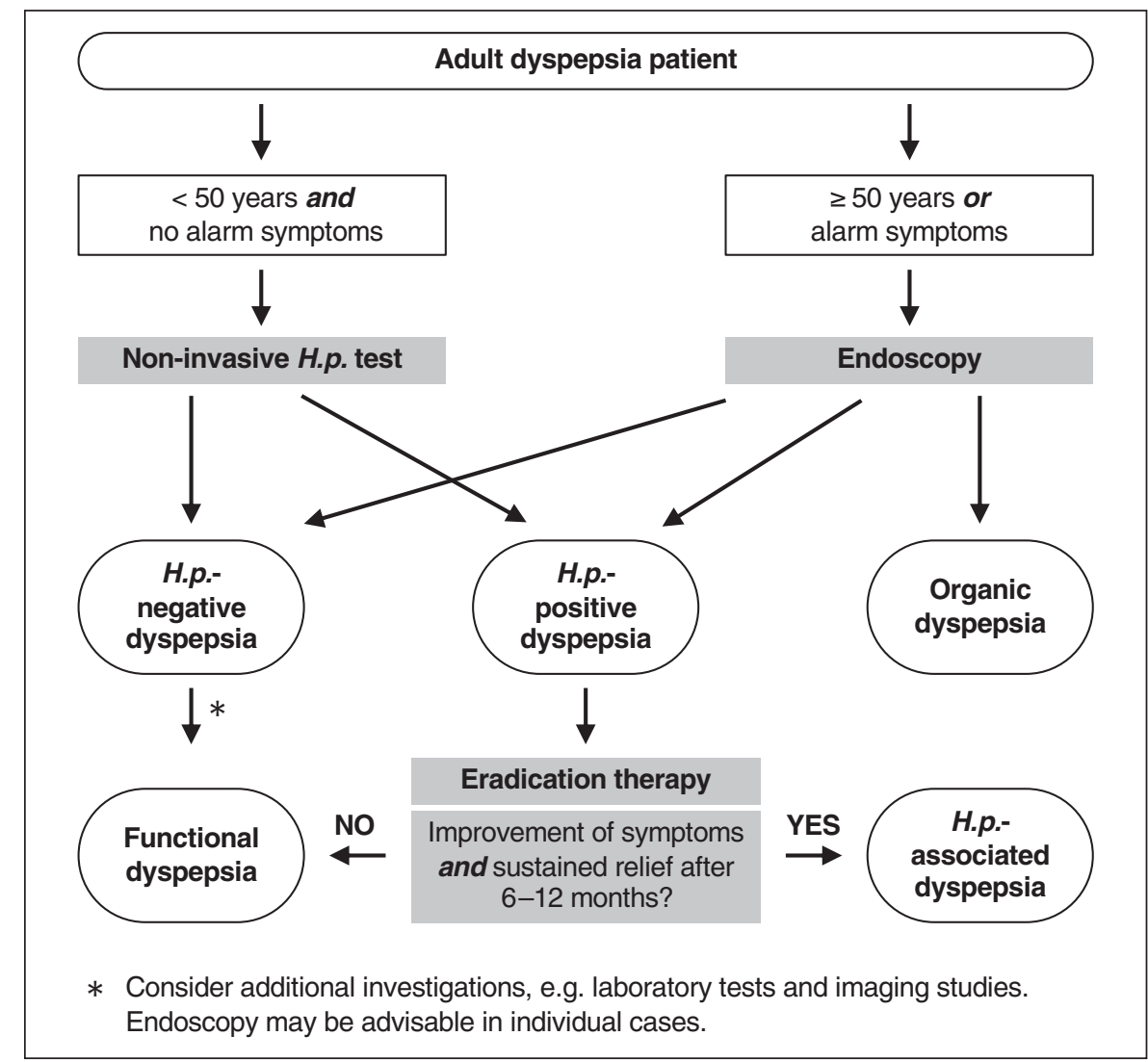

Based on these findings, current guidelines recommend a noninvasive test-and-treat strategy for $H$. pylori in patients with uninvestigated dyspepsia without alarm features and under 40 or 60 years, depending on the guideline $[43,44]$. Serologic tests for $H$. pylori cannot discriminate between current and past infection, and therefore only UBT or fecal antigen test (FAT) should be applied in this setting. Serologic biomarkers for gastric atrophy (e.g., gastrin and pepsinogen I/II) and autoimmunity (e.g., parietal cell antibodies) were developed for risk stratification in noninvasive gastric cancer screening of asymptomatic individuals and for determining the etiology of gastritis, respectively [45-48]. Their role in the workup of dyspepsia has yet to be studied.

Endoscopy is recommended in older patients or when alarm symptoms or features are present, which include dysphagia or odynophagia, persistent vomiting, gastrointestinal bleeding or evidence of iron deficiency anemia, unintentional weight loss, or palpable abdominal mass. It has to be noted that the predictive value of alarm features is limited: in a meta-analysis, the positive likelihood ratio for malignancy in the presence of one or more alarm features is 2.74 (95\% CI: 1.47-5.24), and the area under the pooled summary receiver operator curve for the diagnosis of upper gastrointestinal malignancy using alarm symptoms is 0.8 . This resulted in the ACG/CAG suggestion not to use endoscopy even in the presence of alarm features to exclude upper gastrointestinal neoplasia in patients under the age of 60 . However, the quality of evidence is moderate, and the guideline admits that indeed some patients $<60$ years with alarm features would warrant endoscopy, for example, in the case of prominent features, combinations of several features, or if features like progressive dysphagia or weight loss in the absence of epigastric pain were present [43]. Also, a family history may guide the decision for endoscopy, since individuals with a first-degree relative with gastric cancer have a 2.5 -fold gastric cancer risk [49]. As a pragmatic approach, we recommend noninvasive test-and-treat in patients under 50 years with absence of alarm features and endoscopic evaluation in all other patients. After a negative noninvasive test, empiric PPI therapy is appropriate. A gastroenterologist's decision to perform endoscopy should always take the individual patient's clinical presentation and risk profile into account, and further workup including laboratory testing and imaging studies may be indicated (Fig. 1). 


\section{Endoscopy in the Patient with Dyspepsia}

Upper endoscopy for evaluation of dyspepsia should be a complete esophagogastroduodenoscopy (EGD) and routinely include gastric biopsies to specifically identify gastritis, advanced gastric lesions, and neoplasia. A systematic endoscopy protocol with use of image enhancement and clear photographic documentation of gastric regions should be used with a suggested minimum examination time of $7 \mathrm{~min}$ [50]. The importance of careful macroscopic examination was confirmed in a recent Slovenian single-center retrospective cohort study: in 29,617 EGDs performed, 422 upper GI cancers were diagnosed, and the rate of missed gastric cancers at initial evaluation was $7.3 \%(26 / 354)$ (95\% CI: 4.9-10.6\%) and 4.4\% (95\% CI: $0.9-12.4 \%)$ for esophageal cancers (3/68), based on data matching with the Slovenian Cancer Registry database. Missed cancers were defined as those diagnosed within 36 months after a negative EGD. Three-year survival of missed gastric cancer cases was 12\% (95\% CI: $1-25 \%$ ) and $31 \%$ in patients where gastric cancer was detected (95\% CI: $26-36 \% ; p=0.043)$ and 0 versus $9 \%(95 \%$ CI: $1-17 \% ; p=0.121)$ for esophageal cancer [51].

Every EGD for the evaluation of dyspepsia must include sampling of biopsies according to the Sydney protocol, that is, randomly from both the lesser and greater curvature of the antrum and corpus and incisura, plus from visible suspect lesions. Histopathological assessment must define the etiology of gastritis and the presence of atrophy, intestinal metaplasia, and dysplasia. The severity of gastritis should be graded according to the operative link for gastritis assessment (OLGA) and the operative link for gastric intestinal metaplasia (OLGIM) system. Based on standardized biopsy sampling (Sydney protocol) and histopathological assessment, this staging system integrates both degree and topography of atrophy and intestinal metaplasia into stages $0-I V$.

\section{Management and Surveillance of Gastritis}

Long-term exposure to $H$. pylori is associated with increased risk of progression along the precancerous cascade [52]. H. pylori eradication can partly reverse this progression and has proven to significantly reduce gastric cancer incidence and mortality, both in Asian and Caucasian populations: in an analysis of data from a public hospital database in Hong Kong, treatment of $H$. pylori was associated with a significantly reduced risk of gastric cancer 10 or more years after eradication, especially in subjects older than 60 years (SIR 0.42; 95\% CI: 0.42-0.84; $p=0.02)$ and aged $40-59$ years (SIR 0.32; 95\% CI: $0.08-$ $0.88 ; p=0.04$ ) [53]. In a Swedish nationwide database analysis between 2005 and 2012, the risk of gastric adenocarcinoma decreased over time after $H$. pylori eradication treatment, compared to a matched background population, with SIR $=8.65$ (95\% CI: 6.37-11.46) for $1-3$ years, $\mathrm{SIR}=2.02(95 \%$ CI: $1.25-3.09)$ for $3-5$ years, and SIR = 0.31 (95\% CI: 0.11-0.67) for 5-7.5 years after $H$. pylori treatment. When restricted to noncardia adenocarcinomas, the corresponding SIRs were 10.74 (95\% CI: 7.7714.46), 2.67 (95\% CI: 1.63-4.13), and 0.43 (95\% CI: $0.16-$ 0.93 ), respectively [54]. Recently, this effect has been confirmed in a meta-analysis, which quantified the reduction in gastric cancer incidence after $H$. pylori eradication with $\mathrm{RR}=0.54$ (95\% CI: $0.40-0.72, \mathrm{NNT}=72)$ and gastric cancer mortality with $\mathrm{RR}=0.61$ (95\% CI: $0.40-0.92, \mathrm{NNT}=$ 135) [55].

Based on these findings, current guidelines recommend $H$. pylori eradication in all infected individuals for gastric cancer prevention, irrespective of symptoms [56]. If $H$. pylori has been detected and treated, eradication success must be confirmed. If there is no indication for a short-term repeat endoscopy, for example, for gastric ulcer or dysplasia, eradication control is recommended via a noninvasive test (UBT or FAT) a minimum 4 weeks after completion of antibiotic therapy and 2 weeks after stopping PPIs [18, 56-59].

$H$. pylori eradication can stop progression along the precancerous cascade and may even reverse preneoplastic changes [60-65]. However, advanced gastric lesions like severe corpus-predominant atrophy or intestinal metaplasia are likely irreversible. Thus, some patients require long-term surveillance based on the severity of gastritis and the presence and topography of preneoplastic lesions. Patients with atrophy and/or intestinal metaplasia affecting both antral and corpus mucosa are at highest risk of developing gastric cancer. A large body of evidence supports the reliability of the OLGA/OLGIM classification in predicting the progression risk of atrophy and metaplasia to neoplasia: in a cross-sectional cohort, benign gastric conditions consistently clustered in OLGA/ OLGIM stages 0-II, whereas advanced preneoplastic lesions clustered in stages III-IV $(p<0.001)$ [66]. In a 5 -year follow-up study of 1,755 patients, incident neoplastic lesions developed only in patients with OLGA stages III-IV [67]. In a retrospective analysis of 7,436 patients undergoing EGD for evaluation of dyspepsia at the University of Padua Hospital from 2007 to 2011, subsequent data retrieval from regional health registries re- 
vealed that OLGA stage at the index EGD was significantly associated with rate of gastric neoplasia after a mean follow-up of 6.3 years (OLGA 0 , rate $=0.03$ per 1,000 person-years; OLGA I, rate $=0.34$; OLGA II, rate $=1.48$; OLGA III, rate $=19.1$; OLGA IV, rate $=41.2)$ [68].

A meta-analysis of prospective case-control studies confirmed a significant association between the OLGA/ OLGIM stages III/IV and gastric cancer development [69]. Based on this evidence, the updated international guideline on the management of precancerous conditions and lesions in the stomach (MAPS II) recommends no surveillance in patients with mild to moderate atrophy restricted to the antrum. Also, in most patients with intestinal metaplasia at a single location, surveillance is not advised if a high-quality endoscopy with biopsies has excluded advanced stages of atrophic gastritis. Only in patients with intestinal metaplasia at a single location but with a family history of gastric cancer, or with incomplete intestinal metaplasia, or with persistent $H$. pylori gastritis, endoscopic surveillance with image enhancement and guided biopsies after 3 years may be considered. Patients with severe atrophic changes or intestinal metaplasia in both antrum and corpus (OLGA/OLGIM stages III/IV) should be followed up with high-quality endoscopy every 3 years. Patients with OLGA/OLGIM stages III/IV and with a family history of gastric cancer may even benefit from 1- to 2-year follow-up intervals [70].

\section{Conclusion}

Diagnostic assessment of patients with dyspepsia requires their stratification according to patient age, presence or absence of alarm symptoms, family history, and comorbidities. Noninvasive testing for $H$. pylori is most beneficial and cost-effective compared to other strategies in young patients with dyspeptic symptoms. Elderly patients and those with alarm symptoms should undergo upper gastrointestinal endoscopy, in addition to complementary diagnostics such as ultrasound and laboratory parameters. The detection of $H$. pylori always demands for eradication therapy. Treating $H$. pylori in patients with dyspepsia provides symptom relief in a subset of patients, and the benefit of $H$. pylori eradication extends to prevention of gastric cancer by curing the gastritis. Endoscopic and histological follow-up is recommended in patients in whom severe gastritis is detected during initial diagnostic workup.

\section{Take Home}

1. Dyspepsia at the specialist level demands for identifying the cause and selecting the adequate therapy.

2. H. pylori gastritis is an infectious disease, a specific entity of dyspepsia and a significant risk for gastric cancer.

3. H. pylori eradication confers a symptomatic benefit in a subset of dyspeptic patients and reduces gastric cancer risk and should be offered to all infected individuals.

4. Noninvasive test-and-treat for H. pylori is recommended in younger patients with dyspepsia and without alarm features.

5. Endoscopy with a standardized biopsy protocol and histopathological assessment is recommended in elderly patients with dyspepsia or in the presence of alarm features.

6. High-risk gastric lesions require endoscopic surveillance.

\section{Statement of Ethics}

The research was conducted in accordance with the World Medical Association Declaration of Helsinki.

\section{Conflict of Interest Statement}

L.M. and C.S. report no conflicts of interest. P.M. is Editor-inChief of the journal Digestive Diseases. Final decisions regarding the manuscript were made by an independent guest editor based on comments made by external reviewers.

\section{Funding Sources}

P.M. and C.S. were supported by the EMGASTA project (DRKS-ID: DRKS00009737), carried out within the research group "Autonomie im Alter" of Saxony-Anhalt, Germany, and supported by the European Commission through the Europäischer Fond für Regionale Entwicklung, as well as by the regional Ministry of Economy, Science and Digitalization. C.S. was supported by CRC 854 , a research program by the German research funding organization DFG. C.S. is supported by the HelicoPTER and ERANET-BAVARIA projects (TTU 06.714_00 and TTU 06.827) by the Deutsches Zentrum für Infektionsforschung DZIF.

\section{Author Contributions}

L.M. wrote the manuscript. C.S. and P.M. reviewed the manuscript. 


\section{References}

1 Stanghellini V, Chan FK, Hasler WL, Malagelada JR, Suzuki H, Tack J, et al. Gastroduodenal disorders. Gastroenterology. 2016;150(6): 1380-92.

2 Sperber AD, Bangdiwala SI, Drossman DA, Ghoshal UC, Simren M, Tack J, et al. Worldwide prevalence and burden of functional gastrointestinal disorders, results of Rome Foundation Global Study. Gastroenterology. 2021;160(1):99-114.e3.

3 Ford AC, Marwaha A, Sood R, Moayyedi P. Global prevalence of, and risk factors for, uninvestigated dyspepsia: a meta-analysis. Gut. 2015;64(7):1049-57.

4 Ford AC, Forman D, Bailey AG, Axon AT, Moayyedi P. Initial poor quality of life and new onset of dyspepsia: results from a longitudinal 10-year follow-up study. Gut. 2007; 56(3):321-7.

5 Lacy BE, Weiser KT, Kennedy AT, Crowell MD, Talley NJ. Functional dyspepsia: the economic impact to patients. Aliment Pharmacol Ther. 2013;38(2):170-7.

6 Moayyedi P, Mason J. Clinical and economic consequences of dyspepsia in the community. Gut. 2002;50(Suppl 4):iv10-2.

7 Camilleri M, Dubois D, Coulie B, Jones M, Kahrilas PJ, Rentz AM, et al. Prevalence and socioeconomic impact of upper gastrointestinal disorders in the United States: results of the US Upper Gastrointestinal Study. Clin Gastroenterol Hepatol. 2005;3(6):543-52.

8 Brook RA, Kleinman NL, Choung RS, Melkonian AK, Smeeding JE, Talley NJ. Functional dyspepsia impacts absenteeism and direct and indirect costs. Clin Gastroenterol Hepatol. 2010;8(6):498-503.

9 Vakil N, Talley N, van Zanten SV, Flook N, Persson T, Björck E, et al. Cost of detecting malignant lesions by endoscopy in 2741 primary care dyspeptic patients without alarm symptoms. Clin Gastroenterol Hepatol. 2009; 7(7):756-61.

10 Zagari RM, Eusebi LH, Rabitti S, Cristoferi L, Vestito A, Pagano N, et al. Prevalence of upper gastrointestinal endoscopic findings in the community: a systematic review of studies in unselected samples of subjects. J Gastroenterol Hepatol. 2016;31(9):1527-38.

11 Drossman DA. Functional gastrointestinal disorders: history, pathophysiology, clinical features and rome iv. Gastroenterology. 2016.

12 Drossman DA, Hasler WL. Rome IV-functional gi disorders: disorders of gut-brain interaction. Gastroenterology. 2016;150(6): 1257-61.

13 Hooi JKY, Lai WY, Ng WK, Suen MMY, Underwood FE, Tanyingoh D, et al. Global Prevalence of helicobacter pylori infection: systematic review and meta-analysis. Gastroenterology. 2017;153(2):420-9.

14 Robinson K, Atherton JC. The spectrum of helicobacter-mediated diseases. Annu Rev Pathol. 2021;16:123-44.
15 Plummer M, Franceschi S, Vignat J, Forman D, de Martel C. Global burden of gastric cancer attributable to Helicobacter pylori. Int J Cancer. 2015;136(2):487-90.

16 Plummer M, de Martel C, Vignat J, Ferlay J, Bray F, Franceschi S. Global burden of cancers attributable to infections in 2012: a synthetic analysis. Lancet Glob Health. 2016;4(9): e609-16.

17 Correa P, Houghton J. Carcinogenesis of Helicobacter pylori. Gastroenterology. 2007; 133(2):659-72.

18 Sugano K, Tack J, Kuipers EJ, Graham DY, El-Omar EM, Miura S, et al. Kyoto global consensus report on Helicobacter pylori gastritis. Gut. 2015;64(9):1353-67.

19 Moayyedi P, Forman D, Braunholtz D, Feltbower R, Crocombe W, Liptrott M, et al. The proportion of upper gastrointestinal symptoms in the community associated with Helicobacter pylori, lifestyle factors, and nonsteroidal anti-inflammatory drugs. Leeds HELP Study Group. Am J Gastroenterol. 2000; 95(6):1448-55.

20 Wildner-Christensen M, Hansen JM, De Muckadell OB. Risk factors for dyspepsia in a general population: non-steroidal anti-inflammatory drugs, cigarette smoking and unemployment are more important than Helicobacter pylori infection. Scand J Gastroenterol. 2006;41(2):149-54

21 Rosenstock S, Kay L, Rosenstock C, Andersen LP, Bonnevie O, Jørgensen T. Relation between Helicobacter pylori infection and gastrointestinal symptoms and syndromes. Gut. 1997;41(2):169-76.

22 Fang YJ, Liou JM, Chen CC, Lee JY, Hsu YC, Chen MJ, et al. Distinct aetiopathogenesis in subgroups of functional dyspepsia according to the Rome III criteria. Gut. 2015;64(10): 1517-28.

23 Blum AL, Talley NJ, O’Moráin C, van Zanten SV, Labenz J, Stolte M, et al. Lack of effect of treating Helicobacter pylori infection in patients with nonulcer dyspepsia. Omeprazole plus clarithromycin and amoxicillin effect one year after treatment (OCAY) Study Group. N Engl J Med. 1998;339(26):1875-81.

24 Talley NJ, Janssens J, Lauritsen K, Rácz I, Bolling-Sternevald E. Eradication of Helicobacter pylori in functional dyspepsia: randomised double blind placebo controlled trial with 12 months' follow up. The Optimal Regimen Cures Helicobacter Induced Dyspepsia (ORCHID) Study Group. Bmj. 1999; 318(7187):833-7.

25 Talley NJ, Vakil N, Ballard ED, Fennerty MB. Absence of benefit of eradicating Helicobacter pylori in patients with nonulcer dyspepsia. N Engl J Med. 1999;341(15):1106-11.

26 Bruley Des Varannes S, Fléjou JF, Colin R, Zaïm M, Meunier A, Bidaut-Mazel C. There are some benefits for eradicating Helicobacter pylori in patients with non-ulcer dyspepsia. Aliment Pharmacol Ther. 2001;15(8):1177-85.
27 Malfertheiner P, MOssner J, Fischbach W, Layer P, Leodolter A, Stolte M, et al. Helicobacter pylori eradication is beneficial in the treatment of functional dyspepsia. Aliment Pharmacol Ther. 2003;18(6):615-25.

28 Mazzoleni LE, Sander GB, Francesconi CF, Mazzoleni F, Uchoa DM, De Bona LR, et al. Helicobacter pylori eradication in functional dyspepsia: HEROES trial. Arch Intern Med. 2011;171(21):1929-36.

29 Lan L, Yu J, Chen YL, Zhong YL, Zhang H, Jia $\mathrm{CH}$, et al. Symptom-based tendencies of Helicobacter pylori eradication in patients with functional dyspepsia. World J Gastroenterol. 2011;17(27):3242-7.

30 Kim SE, Park YS, Kim N, Kim MS, Jo HJ, Shin $\mathrm{CM}$, et al. Effect of Helicobacter pylori eradication on functional dyspepsia. J Neurogastroenterol Motil. 2013;19(2):233-43.

31 Wildner-Christensen M, Møller Hansen J, Schaffalitzky De Muckadell OB. Rates of dyspepsia one year after Helicobacter pylori screening and eradication in a Danish population. Gastroenterology. 2003;125(2):372-9.

32 Laine L, Schoenfeld P, Fennerty MB. Therapy for Helicobacter pylori in patients with nonulcer dyspepsia. A meta-analysis of randomized, controlled trials. Ann Intern Med. 2001; 134(5):361-9.

33 Moayyedi P, Soo S, Deeks JJ, Delaney B, Harris $\mathrm{A}$, Innes $\mathrm{M}$, et al. WITHDRAWN: eradication of Helicobacter pylori for non-ulcer dyspepsia. Cochrane Database Syst Rev. 2011(2): CD002096.

34 Zhao B, Zhao J, Cheng WF, Shi WJ, Liu W, Pan XL, et al. Efficacy of Helicobacter pylori eradication therapy on functional dyspepsia: a meta-analysis of randomized controlled studies with 12-month follow-up. J Clin Gastroenterol. 2014;48(3):241-7.

35 Kang SJ, Park B, Shin CM. Helicobacter pylori Eradication therapy for functional dyspepsia: a meta-analysis by region and $\mathrm{H}$. pylori Prevalence. J Clin Med. 2019;8(9):1324.

36 Ben-Menachem T, Ben-Menachem T, Decker GA, Early DS, Evans J, Fanelli RD, et al. Adverse events of upper GI endoscopy. Gastrointest Endosc. 2012;76(4):707-18.

37 Lassen AT, Pedersen FM, Bytzer P, Schaffalitzky de Muckadell OB. Helicobacter pylori test-and-eradicate versus prompt endoscopy for management of dyspeptic patients: a randomised trial. Lancet. 2000;356(9228): 455-60.

38 Lassen AT, Hallas J, Schaffalitzky de Muckadell OB. Helicobacter pylori test and eradicate versus prompt endoscopy for management of dyspeptic patients: 6.7 year follow up of a randomised trial. Gut. 2004;53(12):1758-63.

39 McColl KE, Murray LS, Gillen D, Walker A, Wirz A, Fletcher J, et al. Randomised trial of endoscopy with testing for Helicobacter pylori compared with non-invasive $H$. pylori testing alone in the management of dyspepsia. BMJ. 2002;324(7344):999-1002. 
40 Arents NL, Thijs JC, van Zwet AA, Oudkerk Pool M, Gotz JM, van de Werf GT, et al. Approach to treatment of dyspepsia in primary care: a randomized trial comparing "test-andtreat" with prompt endoscopy. Arch Intern Med. 2003;163(13):1606-12.

41 Duggan AE, Elliott CA, Miller P, Hawkey CJ, Logan RF. Clinical trial: a randomized trial of early endoscopy, Helicobacter pylori testing and empirical therapy for the management of dyspepsia in primary care. Aliment Pharmacol Ther. 2009;29(1):55-68.

42 Mahadeva S, Chia YC, Vinothini A, Mohazmi M, Goh KL. Cost-effectiveness of and satisfaction with a Helicobacter pylori "test and treat" strategy compared with prompt endoscopy in young Asians with dyspepsia. Gut. 2008; 57(9):1214-20.

43 Moayyedi P, Lacy BE, Andrews CN, Enns RA, Howden CW, Vakil N. ACG and CAG clinical guideline: management of dyspepsia. Am J Gastroenterol. 2017;112(7):988-1013.

$44 \mathrm{Oh} \mathrm{JH}$, Kwon JG, Jung HK, Tae CH, Song KH, Kang SJ, et al. Clinical practice guidelines for functional dyspepsia in Korea. J Neurogastroenterol Motil. 2020;26(1):29-50.

45 Zagari RM, Rabitti S, Greenwood DC, Eusebi LH, Vestito A, Bazzoli F. Systematic review with meta-analysis: diagnostic performance of the combination of pepsinogen, gastrin- 17 and anti-Helicobacter pylori antibodies serum assays for the diagnosis of atrophic gastritis. Aliment Pharmacol Ther. 2017;46(7): 657-67.

46 Selgrad M, Bornschein J, Kandulski A, Weigt J, Roessner A, Wex T, et al. Combined gastric and colorectal cancer screening: a new strategy. Int J Mol Sci. 2018;19(12):3845.

47 Song M, Camargo MC, Weinstein SJ, Murphy G, Freedman ND, Koshiol J, et al. Serum pepsinogen 1 and anti-Helicobacter pylori IgG antibodies as predictors of gastric cancer risk in Finnish males. Aliment Pharmacol Ther. 2018;47(4):494-503.

48 Neumann WL, Coss E, Rugge M, Genta RM. Autoimmune atrophic gastritis: pathogenesis, pathology and management. Nat Rev Gastroenterol Hepatol. 2013;10(9):529-41.

49 Yaghoobi M, McNabb-Baltar J, Bijarchi R, Hunt RH. What is the quantitative risk of gastric cancer in the first-degree relatives of patients? A meta-analysis. World J Gastroenterol. 2017;23(13):2435-42.

50 Banks M, Graham D, Jansen M, Gotoda T, Coda S, di Pietro M, et al. British Society of Gastroenterology guidelines on the diagnosis and management of patients at risk of gastric adenocarcinoma. Gut. 2019;68(9):1545-75.
51 Gavric A, Hanzel J, Zagar T, Zadnik V, Plut S, Stabuc B. Survival outcomes and rate of missed upper gastrointestinal cancers at routine endoscopy: a single centre retrospective cohort study. Eur J Gastroenterol Hepatol. 2020;32(10):1312-21.

52 Mera RM, Bravo LE, Camargo MC, Bravo JC, Delgado AG, Romero-Gallo J, et al. Dynamics of Helicobacter pylori infection as a determinant of progression of gastric precancerous lesions: 16-year follow-up of an eradication trial. Gut. 2018;67(7):1239-46.

53 Leung WK, Wong IOL, Cheung KS, Yeung KF, Chan EW, Wong AYS, et al. Effects of Helicobacter pylori treatment on incidence of gastric cancer in older individuals. Gastroenterology. 2018;155(1):67-75.

54 Doorakkers E, Lagergren J, Engstrand L, Brusselaers N. Helicobacter pylori eradication treatment and the risk of gastric adenocarcinoma in a Western population. Gut. 2018;67(12):2092-6.

55 Ford AC, Yuan Y, Moayyedi P. Helicobacter pylori eradication therapy to prevent gastric cancer: systematic review and meta-analysis. Gut. 2020;69(12):2113-21.

56 Liou JM, Malfertheiner P, Lee YC, Sheu BS, Sugano K, Cheng HC, et al. Screening and eradication of Helicobacter pylori for gastric cancer prevention: the Taipei global consensus. Gut. 2020;69(12):2093-112.

57 Chey WD, Leontiadis GI, Howden CW, Moss SF. ACG clinical guideline: treatment of $\mathrm{He}-$ licobacter pylori infection. Am J Gastroenterol. 2017;112(2):212-39.

58 Malfertheiner P, Megraud F, O'Morain CA, Gisbert JP, Kuipers EJ, Axon AT, et al. Management of Helicobacter pylori infection-the Maastricht V/florence consensus report. Gut. 2017;66(1):6-30.

59 Mahachai V, Vilaichone RK, Pittayanon R, Rojborwonwitaya J, Leelakusolvong S, Maneerattanaporn $\mathrm{M}$, et al. Helicobacter pylori management in ASEAN: the Bangkok consensus report. J Gastroenterol Hepatol. 2018; 33(1):37-56.

60 Kuipers EJ, Nelis GF, Klinkenberg-Knol EC, Snel P, Goldfain D, Kolkman JJ, et al. Cure of Helicobacter pylori infection in patients with reflux oesophagitis treated with long term omeprazole reverses gastritis without exacerbation of reflux disease: results of a randomised controlled trial. Gut. 2004;53(1):1220.
61 Mera R, Fontham ET, Bravo LE, Bravo JC, Piazuelo MB, Camargo MC, et al. Long term follow up of patients treated for Helicobacter pylori infection. Gut. 2005;54(11):1536-40.

62 Arkkila PE, Seppälä K, Färkkilä MA, Veijola L, Sipponen P. Helicobacter pylori eradication in the healing of atrophic gastritis: a oneyear prospective study. Scand J Gastroenterol. 2006;41(7):782-90.

63 Kodama M, Murakami K, Okimoto T, Abe T, Nakagawa Y, Mizukami K, et al. Helicobacter pylori eradication improves gastric atrophy and intestinal metaplasia in long-term observation. Digestion. 2012;85(2):126-30.

64 Kodama M, Murakami K, Okimoto T, Sato R, Uchida M, Abe T, et al. Ten-year prospective follow-up of histological changes at five points on the gastric mucosa as recommended by the updated Sydney system after Helicobacter pylori eradication. J Gastroenterol. 2012;47(4):394-403.

65 Hwang YJ, Kim N, Lee HS, Lee JB, Choi YJ, Yoon $\mathrm{H}$, et al. Reversibility of atrophic gastritis and intestinal metaplasia after Helicobacter pylori eradication: a prospective study for up to 10 years. Aliment Pharmacol Ther. 2018;47(3):380-90

66 Rugge M, Meggio A, Pennelli G, Piscioli F, Giacomelli L, De Pretis G, et al. Gastritis staging in clinical practice: the OLGA staging system. Gut. 2007;56(5):631-6.

67 Rugge M, Meggio A, Pravadelli C, Barbareschi M, Fassan M, Gentilini M, et al. Gastritis staging in the endoscopic follow-up for the secondary prevention of gastric cancer: a 5 -year prospective study of 1755 patients. Gut. 2019;68(1):11-7.

68 Rugge M, Genta RM, Fassan M, Valentini E, Coati I, Guzzinati S, et al. OLGA gastritis staging for the prediction of gastric cancer risk: a long-term follow-up study of 7436 patients. Am J Gastroenterol. 2018;113(11):1621-8.

69 Yue H, Shan L, Bin L. The significance of OLGA and OLGIM staging systems in the risk assessment of gastric cancer: a systematic review and meta-analysis. Gastric Cancer. 2018; 21(4):579-87.

70 Pimentel-Nunes P, Libânio D, Marcos-Pinto R, Areia M, Leja M, Esposito G, et al. Management of epithelial precancerous conditions and lesions in the stomach (MAPS II): European Society of Gastrointestinal Endoscopy (ESGE), European Helicobacter and Microbiota Study Group (EHMSG), European Society of Pathology (ESP), and Sociedade Portuguesa de Endoscopia Digestiva (SPED) guideline update 2019. Endoscopy. 2019; 51(4):365-88. 